\title{
Biomassa residual agrícola e florestal na produção de compactados para geração de energia
}

\author{
Quantification of agricultural and forestry waste biomass to production of compacts for power generation
}

\section{Daniela Letícia Nones, Martha Andreia Brand*, Camilla Gabriela Melo Ampessan e Gustavo Friederichs}

Recebido em 06/04/2016 / Aceito em 08/12/2016

\section{RESUMO}

O objetivo deste trabalho foi quantificar e localizar regionalmente, no Estado de Santa Catarina, a biomassa residual florestal e agrícola com potencial para o uso na produção de compactados para geração de energia. $O$ estudo envolveu dados da produção anual agrícola e florestal do ano de 2012. Para determinar a quantidade de resíduos agrícolas (culturas temporárias e perenes) ou florestais (silvicultura) gerada por cada cultura, foi utilizado um valor denominado coeficiente técnico encontrado na literatura. Foram abordados dois critérios para discussão dos dados: quantidade de resíduos gerada e sua localização geográfica. A cultura de milho foi a que gerou a maior quantidade de resíduos em 2012, seguida da silvicultura, cultura de arroz e de soja. As mesorregiões Oeste Catarinense, Norte Catarinense e Serrana foram as que mais geraram resíduos em 2012. Os resíduos da silvicultura e culturas de milho, arroz e soja são os que possuem maior potencial em termos de quantidade e localização para produção de compactados para a geração de energia.

PALAVRAS-CHAVE: energia de biomassa, resíduos de colheita, potencial energético.

\footnotetext{
ABSTRACT

The objective of this study was to quantify and locate regionally in the State of Santa Catarina the agricultural and forestry waste biomass with potential for densification for energy production. The study involved data from annual agricultural and forestry production from the year 2012. A value called technical coefficient, found in the literature, was used to determine the amount of agricultural (from temporary and perennial crops) and forest residues generated for each culture. Two standards were used

Universidade do Estado de Santa Catarina, Lages, SC, Brasil.

*Autor para correspondência <martha.brand@udesc.br>
}

for the discussion of the data: the amount of waste generated and the geographical location. The maize crop generated the biggest amount of waste in 2012, followed by forestry, upland rice and soybeans. The Southern, the Western and the Mountains are the mesoregions that produced the most waste in 2012. Residues from forestry, maize, rice and soybeans are those with the greatest potential in terms of quantity and geographical location for densification for energy production.

KEYWORDS: biomass energy, crop residues, energy potential.

\section{INTRODUÇÃO}

A biomassa vegetal tem ampla abrangência de tipos de materiais, pois engloba todos os organismos formados através do processo de fotossíntese como também os resíduos gerados a partir da utilização dos mesmos, tais como resíduos florestais e agrícolas; matéria orgânica contida nos resíduos industriais, domésticos, comerciais e rurais (BRAND 2010).

A biomassa florestal pode ser entendida como resíduos de plantios florestais, de serrarias de beneficiamento da madeira, indústrias de papel e celulose, fabricação de painéis, dentre outras. Já a biomassa agrícola engloba culturas que também produzem resíduos com potencial energético, como por exemplo, casca de arroz e palha de milho.

Nos processos produtivos agrícolas e florestais, a geração de resíduos pode se tornar um desperdício de produção, visto que estes nem sempre são convertidos em uma nova fonte de renda para as empresas produtoras. Estes resíduos, em muitos casos, são mal manejados, sendo depositados em locais impróprios, como margens de rios, gerando problemas ambientais.

Atualmente, a existência de legislação referente a passivos ambientais exige a gestão adequada dos 
resíduos. A Lei $\mathrm{n}^{\mathrm{o}} 12.305$ de 2 de agosto de 2010, regulamentada pelo Decreto $\mathrm{n}^{\circ} 7.404$, de 23 de dezembro de 2010, que institui a Política Nacional de Resíduos Sólidos (BRASIL 2010) reúne princípios, objetivos, instrumentos, diretrizes, metas e ações adotados pelo Governo Federal, objetivando a gestão integrada e o gerenciamento ambientalmente adequado dos resíduos sólidos. Ou seja, há a necessidade de dar-se um destino ambientalmente adequado para os resíduos, fazendo com que os produtores e empresas geradores busquem alternativas de utilização deste tipo de material, como por exemplo, a transformação em energia.

Segundo BRAND (2007), as vantagens ambientais da utilização de fontes energéticas renováveis, em comparação com aquelas não renováveis, explicam o interesse das empresas e o apoio governamental, além da expansão crescente do uso deste tipo de fonte energética. Aliado a isso, o uso de resíduos florestais e agrícolas para a geração de energia como fonte limpa de combustível é economicamente atraente, pois é uma complementação de renda tanto para quem vende quanto para quem compra e beneficia o resíduo.

Como o Brasil é um dos maiores produtores agrícolas e florestais do mundo, a quantidade de biomassa residual representa um depósito de energia a ser aproveitado, especialmente nas formas de briquetes e pellets (DIAS et al. 2012). O processo de fabricação de briquetes e pellets consiste na densificação da biomassa residual, por meio da aplicação de pressão. $\mathrm{O}$ atrito entre as partículas e a matriz da briquetadeira, ou peletizadora, promove o aquecimento, que por sua vez, contribui para a compactação, elevando a densidade e diminuindo o teor de umidade do produto, aumentando a densidade energética destes combustíveis em comparação com a matéria-prima residual que lhes deu origem.

Para verificar se é possível utilizar biomassa florestal e agrícola para a produção de compactados, para a geração de energia, é necessário levar em consideração quatro importantes aspectos: quantidade, localização, disponibilidade e qualidade energética do resíduo. Em estudos de caráter preliminar, os primeiros itens que devem ser levantados são a quantidade e localização da fonte energética. A quantificação da biomassa se refere à massa ou volume do material em relação a uma unidade de área, enquanto a localização organiza esta quantidade em um limite geográfico que tem implicações diretas sobre o custo de seu uso energético.

A partir destas informações, deve-se verificar a existência de outros usos concorrentes na região e fora dela que possam impactar na disponibilidade do mesmo para o fim proposto. A partir da biomassa disponível, a determinação de algumas propriedades físicas e energéticas, como teor de umidade e poder calorífico, são fundamentais para a definição da viabilidade técnica e econômica da destinação energética do resíduo.

Considerando que este estudo tem caráter preliminar e que o Estado de Santa Catarina necessita de informações sobre o potencial da biomassa vegetal como fonte energética, o objetivo deste trabalho foi quantificar e localizar regionalmente, em Santa Catarina, a biomassa residual florestal e agrícola com potencial para o uso na produção de compactado para geração de energia.

\section{MATERIAL E MÉTODOS}

O levantamento foi realizado no Estado de Santa Catarina e para melhor distribuição das variáveis, os dados foram agrupados nas seis mesorregiões do Estado, de acordo com o Instituto Brasileiro de Geografia e Estatística - IBGE: Oeste Catarinense, Norte Catarinense, Sul Catarinense, Serrana, Vale do Itajaí e Grande Florianópolis. Na Figura 1 é apresentada a disposição das mesorregiões no território catarinense.

O estudo envolveu dados da produção agrícola e florestal anuais, através da coleta de dados indiretos da quantidade de resíduos, ou seja, sem a realização de levantamentos a campo para a quantificação dos mesmos. Os dados da produção para as culturas estudadas foram extraídos da base de dados agregados do IBGE, denominada Produção Agrícola Municipal (PAM), do ano base 2012 (IBGE 2014). Foram selecionadas culturas com produção igual ou superior a 5 toneladas anuais.

Para determinar a quantidade de resíduos agrícolas ou florestais gerados em cada cultura foi utilizado um valor denominado coeficiente técnico. Este coeficiente expressa a quantidade (em toneladas) de resíduos gerados em relação à quantidade do produto produzida e comercializada em cada cultura.

Ressalta-se que o estudo possui caráter de apresentação do potencial total de resíduos, levando em consideração também aqueles que já possuem usos concorrentes ou que sua utilização possa ter 
impedimento de ordem operacional ou ambiental. Assim, foram consideradas todas as culturas anuais ou perenes, potencialmente geradoras de resíduos em alguma etapa do processo de colheita e/ou beneficiamento.

Em relação à quantidade de resíduos, não foi estabelecido um valor mínimo de produção anual do resíduo. A quantidade utilizada para a compactação dependerá do tamanho do investimento realizado e a quantidade de produto final desejado. NONES (2014), em levantamento da cadeia produtiva de pellets em Santa Catarina, verificou que a média da produção mensal de cada uma das empresas estudadas era de 300 toneladas, podendo duplicar durante o período de inverno, quando a demanda pelo produto cresce consideravelmente.

Quanto à localização, foi observado como o resíduo está distribuído pelas mesorregiões e se as mesmas são contíguas, em termos de potencial produtor dos resíduos analisados.

Através da realização de um banco de dados em planilha do software Excel $^{\circledR}$ com as variáveis pesquisadas (cultura, produção, quantidade de resíduos gerados) e uso do software ArcGIS ${ }^{\circledR} 10.1$, elaborouse um mapa cartográfico, em escala de cinza, que representa a quantidade e distribuição geográfica dos resíduos nas mesorregiões do Estado. No mapa, o tom de cinza mais escuro representa a mesorregião com maior geração de resíduos de determinada cultura.

\section{RESULTADOS E DISCUSSÃO}

Na Tabela 1 são apresentados os produtos agrícolas e florestais, tipo de resíduo, local de produção e coeficientes técnicos dos resíduos analisados neste trabalho.

A quantidade de resíduos e sua distribuição em relação às mesorregiões de Santa Catarina são apresentadas na Tabela 2, para a silvicultura e as culturas temporárias mais importantes do Estado, em termos de produção de resíduos.

Segundo dados da PAM (IBGE 2014), a produção catarinense de milho foi de 2.870 .450 toneladas em 2012, representando $12,7 \%$ do total produzido na região Sul e pouco mais de $4 \%$ do total no país.

Para a estimativa da produção de resíduos da cultura do milho, o coeficiente técnico apresentado na Tabela 1 foi utilizado, obtendo-se 7.176.125 toneladas de palhada e 1.722.270 toneladas de sabugo, totalizando 8.898.395 toneladas de resíduos resultantes da cultura e processamento do milho em Santa Catarina.

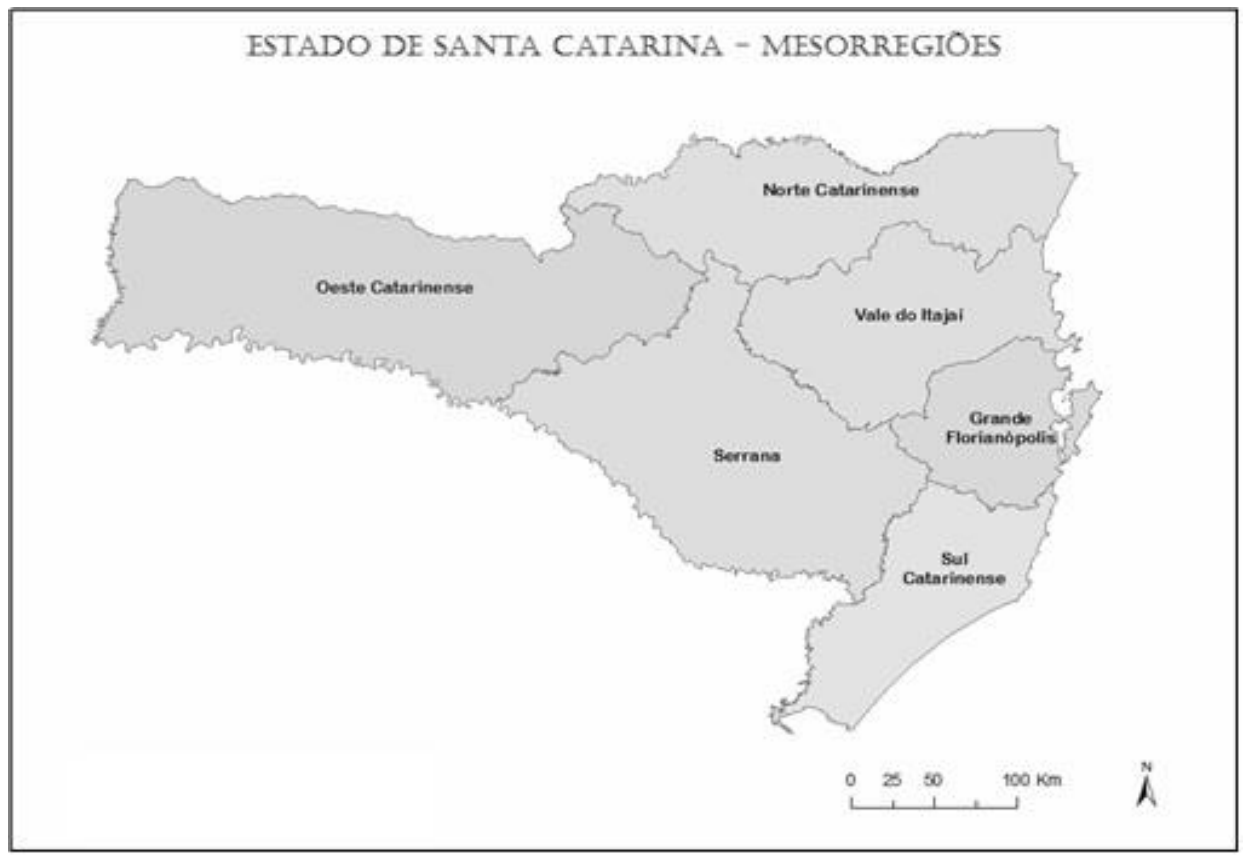

Figura 1 - Mesorregiões do Estado de Santa Catarina.

Figure 1 - Mesoregions of the State of Santa Catarina. 
Tabela 1 - Produto, tipo de resíduo, local de produção e coeficiente técnico dos resíduos.

Table 1 - Product, type, production site and technical coefficient of waste collected.

\begin{tabular}{|c|c|c|c|}
\hline Produto & Tipo de resíduo & Local de produção & $\begin{array}{l}\text { Coeficiente técnico } \\
\text { (t resíduo/t produto) }\end{array}$ \\
\hline Amendoim & Palhada e cascas & Campo e Indústria & $1,07^{1}$ \\
\hline \multirow{2}{*}{ Arroz } & Palhada & Campo & $1,30^{2}$ \\
\hline & Cascas & Indústria & $0,22^{2}$ \\
\hline \multirow{2}{*}{ Cana-de-açúcar } & Palha e Ponteira & Campo & $0,24^{1}$ \\
\hline & Bagaço & Indústria & $0,27^{2}$ \\
\hline Feijão & Palhada e vagem & Campo & $3,67^{1}$ \\
\hline \multirow{2}{*}{ Milho } & Palhada & Campo & $2,50^{2}$ \\
\hline & Sabugo & Indústria & $0,60^{2}$ \\
\hline Soja & Palhada & Campo & $1,40^{1}$ \\
\hline Trigo & Palhada & Campo & $1,40^{2}$ \\
\hline \multirow{3}{*}{ Banana (cacho) } & Folhas & Campo & $1,50^{1}$ \\
\hline & Pseudocaule & Campo & $2,50^{1}$ \\
\hline & Engaço & Indústria & $0,12^{1}$ \\
\hline Maçã & Bagaço & Indústria & $0,25^{1}$ \\
\hline Laranja & Cascas & Indústria & $0,50^{3}$ \\
\hline Uva & Cascas e sementes & Indústria & $0,40^{3}$ \\
\hline Abacate & Cascas e caroços & Indústria & $0,34^{1}$ \\
\hline \multirow{2}{*}{ Madeira } & Ponteira, galhos e cascas & Campo & $0,15^{3}$ \\
\hline & Serragem, cascas e cavacos & Indústria & $0,50^{4}$ \\
\hline
\end{tabular}

Fonte: ${ }^{1}$ ABIB (2011), ${ }^{2}$ DIAS et al. (2012), ${ }^{3}$ SCHNEIDER et al. (2011) e e ${ }^{4}$ CENBIO (2012).

Legenda: $t$ resíduo/t produto - tonelada de resíduo gerada por tonelada de produto.

Tabela 2 - Quantidade e localização regional dos resíduos da silvicultura e culturas temporárias em Santa Catarina (em toneladas).

Table 2 - Quantity and location of forestry and temporary crop residues in Santa Catarina (in tonnes).

\begin{tabular}{|c|c|c|c|c|c|c|c|}
\hline \multirow[b]{2}{*}{ Produto } & \multicolumn{6}{|c|}{ Mesorregião } & \multirow[b]{2}{*}{ Estado } \\
\hline & Oeste & Norte & Serrana & $\begin{array}{l}\text { Vale } \\
\text { Itajaí }\end{array}$ & $\begin{array}{c}\text { Grande } \\
\text { Florianópolis }\end{array}$ & Sul & \\
\hline Milho & 4.387 .219 & 1.912 .506 & 1.491 .506 & 670.759 & 110.487 & 325.981 & 8.898 .395 \\
\hline Madeira & 1.337 .924 & 1.520 .399 & 1.752 .700 & 402.281 & 34.346 & 220.775 & 5.268 .425 \\
\hline Arroz & 1.400 & 232.502 & 520 & 354.801 & 60.271 & 1.018 .268 & 1.667 .762 \\
\hline Soja & 727.551 & 431.259 & 344.243 & 8.513 & - & - & 1.511 .566 \\
\hline Feijão & 152.147 & 58.386 & 159.212 & 21.499 & 7.212 & 26.233 & 424.689 \\
\hline $\begin{array}{l}\text { Cana-de- } \\
\text { açúcar }\end{array}$ & 111.659 & 24.684 & - & 23.011 & 26.852 & 68.309 & 245.515 \\
\hline Trigo & 122.793 & 35.494 & 36.316 & 580 & - & - & 195.182 \\
\hline Amendoim & 450 & - & - & - & - & - & 450 \\
\hline Total & 6.914 .624 & 4.172 .208 & 3.811 .369 & 1.474 .328 & 238.634 & 1.649 .041 & 18.260 .203 \\
\hline
\end{tabular}


A mesorregião Oeste é a maior produtora de resíduos da cultura do milho, com 4.387.219 toneladas geradas em 2012, seguida da mesorregião Norte (1.912.443 toneladas) e serrana (1.491.506 toneladas), conforme representado na Figura 2.

Considerando a questão quantidade, o milho é a cultura mais expressiva em relação à produção de resíduos de todo o Estado, totalizando aproximadamente 8,9 milhões de toneladas geradas em 2012, tendo esta cultura viabilidade para uso na compactação. Algumas mesorregiões contribuem mais expressivamente do que outras. Além disso, as épocas do ano em que este resíduo está disponível em maior quantidade também devem ser consideradas.

Com relação à localização, as três mesorregiões com maior expressão na produção de milho e consequente geração de resíduos são contíguas, o que facilita o transporte do material para uso em unidades de compactação. Esse fato também deve ser levado em consideração para escolha de um local para instalação destas unidades. Ou ainda, pode ser possível a instalação de pequenas unidades em todas as mesorregiões, visto que todas possuem quantidade suficiente de resíduos para a utilização na compactação, considerando uma quantidade mínima mensal de 300 toneladas.

Segundo DIAS et al. (2012), aconselha-se a manutenção de pelo menos $50 \%$ dos resíduos do milho no campo para ciclagem de nutrientes e da matéria orgânica do solo, podendo o restante ser aproveitado para geração de energia. Salienta-se que a empresa produtora de compactados precisará de garantias de recebimento de matéria-prima, para assegurar sua escala de produção. Caso contrário, o empreendimento poderá não prosperar.

No levantamento da silvicultura realizado pelo IBGE, são encontradas quatro destinações dadas aos produtos no Estado, as quais são carvão vegetal, lenha, madeira em tora para papel e celulose e madeira em tora para outras finalidades. Para o cálculo foram consideradas apenas as duas últimas destinações da madeira, visto que o carvão vegetal e a lenha são denominações dadas aos produtos da silvicultura destinados exclusivamente para a geração de energia. Segundo o Centro Nacional de Referência em Biomassa - CENBIO (2012) são considerados resíduos da silvicultura aqueles restantes da colheita florestal, com coeficiente técnico 0,15 e aqueles restantes do processamento da madeira nas indústrias, com coeficiente técnico 0,50 . Para a produção de madeira em toras para papel e celulose, foram considerados apenas os resíduos da colheita florestal, uma vez que as toras são convertidas integralmente para o processo de celulose.

Os dados do ano base 2012 do IBGE (2014) apresentam uma produção de 13.252.026 toneladas de madeira em tora, sendo que $50 \%$ destas foram destinadas à produção de papel e celulose e $50 \%$ para outras finalidades.

A produção de resíduos da silvicultura foi de 5.268.426 toneladas, das quais 3.280.622 toneladas foram resíduos do processamento industrial da madeira. A colheita florestal gerou um montante de 1.987.804 toneladas de resíduos, que englobam folhas, acículas, galhos e ponteira do tronco de árvores.

A localização regional da geração de resíduos da silvicultura em Santa Catarina é apresentada na Figura 3. A mesorregião Serrana concentra grande parte dos resíduos de madeira do Estado, totalizando 1.752.700 toneladas, seguida da mesorregião Norte, com 1.520.399 toneladas e Oeste, com 1.337.924 toneladas de resíduos madeireiros e florestais. Somadas essas três mesorregiões representam aproximadamente 88\% destes resíduos no Estado, representando o grande potencial em relação à quantidade para a utilização dos resíduos para compactação.

Em relação à localização, as mesorregiões com maior produção são vizinhas, facilitando o transporte de material quando houver necessidade.

O setor florestal possui uma estrutura mais organizada em relação às outras culturas abordadas neste estudo, principalmente no que diz respeito à coleta, venda e utilização dos resíduos gerados. Já existe um comércio estabelecido no Estado, principalmente para maravalha e cavacos. Algumas empresas especializaram-se na compra de resíduos e no tratamento adequado deste material, com o objetivo de revendê-lo para empresas que utilizam biomassa como fonte de energia ou para empresas fabricantes de compactados. Estas empresas têm relatado que a distância viável para o transporte de biomassa para a geração de energia é de $80 \mathrm{~km}$, podendo aumentar quando o valor de mercado do resíduo estiver em alta.

A base florestal catarinense é formada principalmente por espécies do gênero Pinus, que tradicionalmente é utilizada para a produção de compactados para a geração de energia. NONES (2014) verificou que todas as empresas no Estado que produzem compactados utilizam maravalha de Pinus spp., obtendo um produto final de ótima qualidade. 


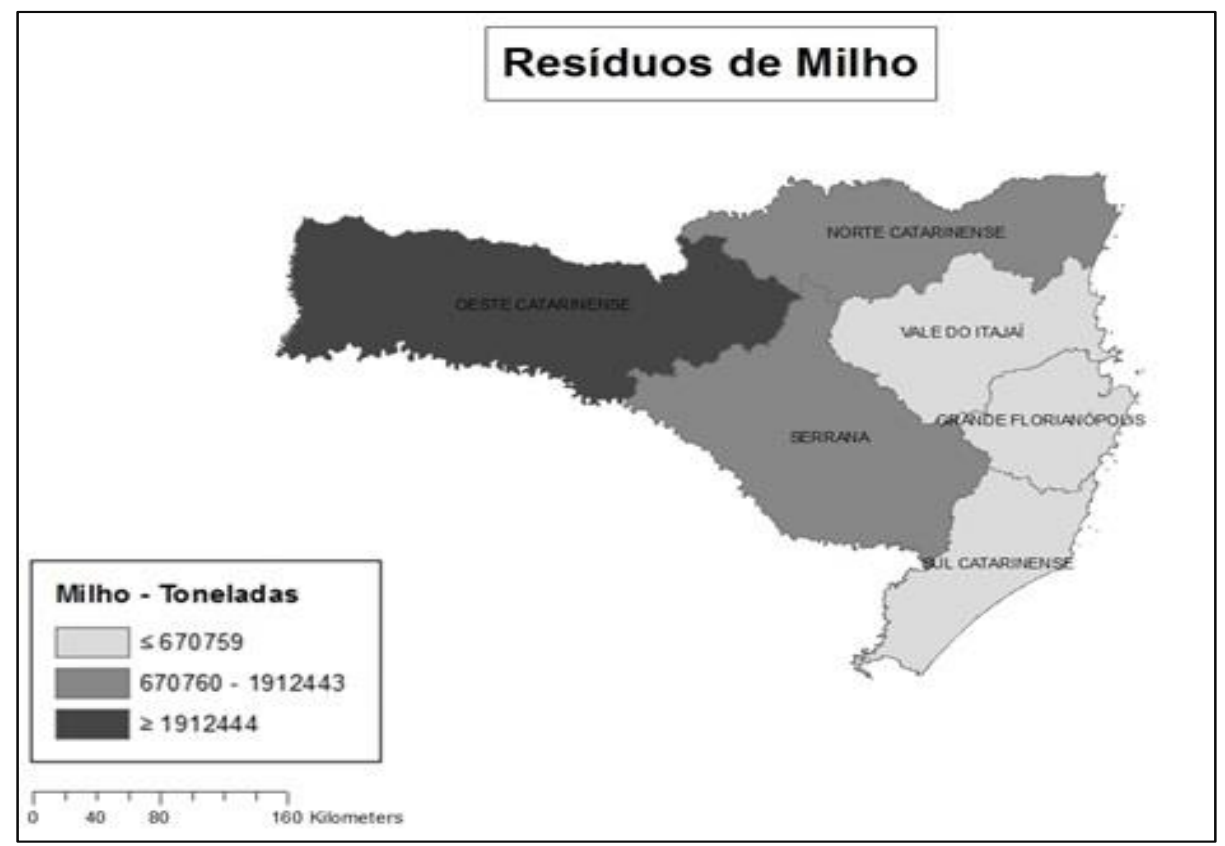

Figura 2 - Mapa ilustrando a distribuição dos resíduos da cultura do milho nas mesorregiões de Santa Catarina. Figure 2 - Map illustrating the distribution of maize residues in the mesoregions of Santa Catarina.

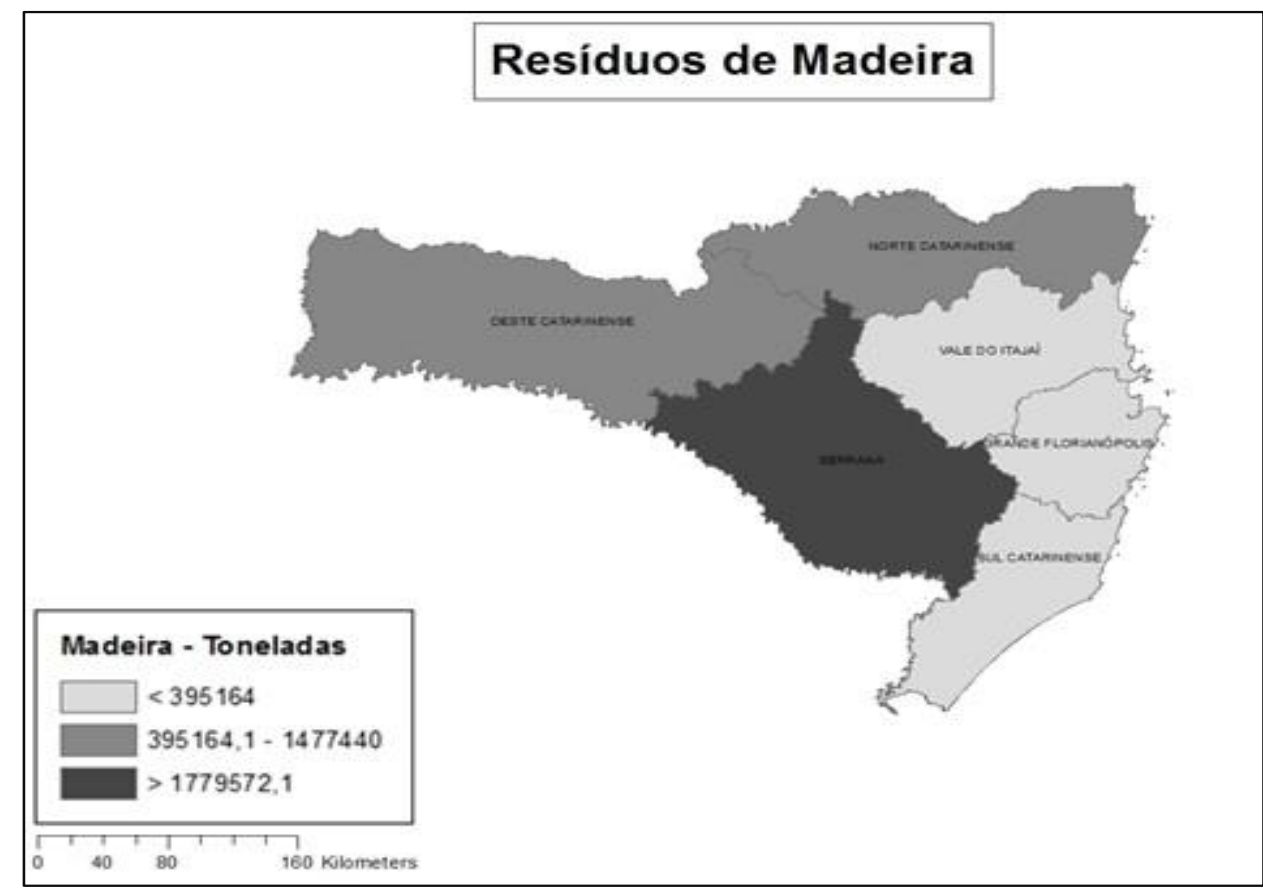

Figura 3 - Mapa ilustrando a disposição dos resíduos da silvicultura nas mesorregiões de Santa Catarina. Figure 3 - Map illustrating the distribution of forestry residues in the mesoregions of Santa Catarina. 
Dados da PAM (IBGE 2014) apresentam que a produção de arroz em Santa Catarina foi de 1.097.212 toneladas em 2012, a qual gera resíduos na fase de colheita, restando palhada no campo com coeficiente técnico 1,30 e na fase de beneficiamento, restando cascas e rejeitos, com coeficiente técnico 0,22 (DIAS et al. 2012). Desta forma, em 2012, foram geradas 1.667.762 toneladas de resíduos oriundos da orizicultura, sendo aproximadamente $14,5 \%$ por cascas de arroz e $85,5 \%$ pela palhada em campo.

A produção de arroz ocorre em todas as mesorregiões do Estado, sendo que a mesorregião Sul Catarinense apresenta a maior produção de resíduos, aproximadamente $61 \%$ (1.018.268 toneladas) do total do Estado, seguida da mesorregião Vale do Itajaí, com aproximadamente 21,3\% (354.801 toneladas), conforme Figura 4.

Os resíduos da cultura de arroz são indicados para o uso na compactação, principalmente na mesorregião Sul, que representa mais da metade da quantidade de resíduos gerados no Estado.

Em relação à localização da produção dos resíduos, percebe-se que a mesorregião que mais produz está distante das outras duas com maior potencial de resíduos disponível. Este fato não impede o uso para compactação, porém pode dificultar o transporte de material, caso haja necessidade.
No que diz respeito à palhada, de acordo com BAZZO et al. (2013), atualmente, há legislação que proíbe a realização de queimadas da palha no campo, após a colheita do arroz. Diante disso, os agricultores incorporam a palha ao solo, com o objetivo de facilitar a sua decomposição. Porém, este processo gera metano $\left(\mathrm{CH}_{4}\right)$, que é considerado mais prejudicial ao meio ambiente do que o dióxido de carbono $\left(\mathrm{CO}_{2}\right)$ gerado na queima. Dessa maneira, torna-se necessário dar a este resíduo uma destinação correta e menos poluente, sendo a compactação uma ótima alternativa do ponto de vista da quantidade de palha de arroz gerada.

A casca de arroz já tem seu uso consolidado, sendo empregada para gerar energia de forma direta para secagem do próprio grão. De acordo com MAYER et al. (2006), além da queima direta para geração de energia na própria beneficiadora, a briquetagem das cascas seria uma forma eficiente do aproveitamento dessa energia, por ganhos de densidade do produto final, que causa aumento de até 2,5 vezes o poder calorífico.

Após a queima da casca nas caldeiras, é gerado um subproduto, denominado cinza de casca de arroz. Até o momento, não existem estudos usando este resíduo para a geração de energia, seu uso está basicamente relacionado ao teor de sílica. Segundo DELLA et al. (2001), este subproduto é rico em sílica

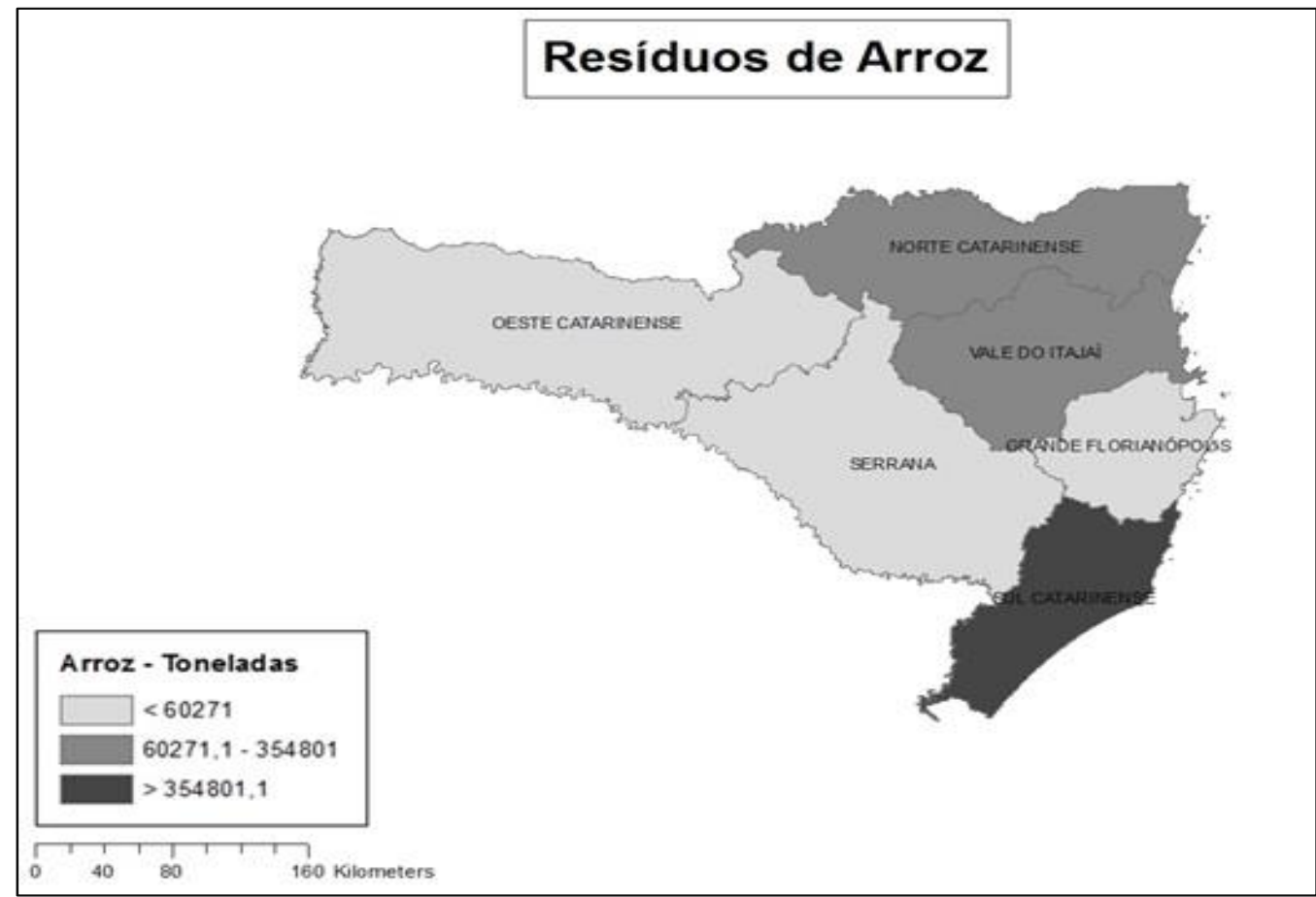

Figura 4 - Mapa ilustrando a disposição dos resíduos da produção de arroz nas mesorregiões de Santa Catarina. Figure 4 - Map illustrating the distribution of rice residues in the mesoregions of Santa Catarina. 
(teores superiores a 90\%), que pode ser usada como componente principal de massas cerâmicas para a produção de refratários silicosos ácidos.

A produção de soja em Santa Catarina foi de 1.079.690 toneladas em 2012, de acordo com o PAM (IBGE 2014). Este valor corresponde a 6\% da produção da região Sul do Brasil e aproximadamente $1,63 \%$ da produção brasileira.

O resíduo proveniente da produção de soja é a palhada que permanece no campo após a colheita. De acordo com o coeficiente técnico apresentado na Tabela 1, o Estado produziu 1.511.566 toneladas de palhada em 2012.

A produção de soja está presente em quatro das seis mesorregiões do Estado, sendo que a mesorregião Oeste contribuiu mais significativamente para o montante de resíduos gerados, em torno de $730 \mathrm{mil}$ toneladas, seguida da Norte, com 430 mil toneladas e Serrana, com 345 mil toneladas, conforme Figura 5.

As três mesorregiões que mais produziram estão localizadas próximas, facilitando o transporte de matéria-prima entre elas. Da mesma forma como ocorre com a cultura do milho, é indicado que metade dos resíduos permaneça no campo para a ciclagem de nutrientes.
No total para o Estado, os resíduos de feijão, cana-de-açúcar, trigo e amendoim somaram 424.689 toneladas, 254.515 toneladas, 195.182 toneladas e 450 toneladas, respectivamente, no ano de 2012. Destas culturas menos expressivas em termos de quantidade de resíduos gerados, somente os resíduos de amendoim geram menos de 3.600 toneladas/ano, que seria o mínimo necessário para uma pequena planta de compactação.

$\mathrm{Na}$ Tabela 3 é apresentada a quantidade de resíduos e sua distribuição em relação às mesorregiões de Santa Catarina, para as culturas perenes mais importantes do Estado, em termos de produção de resíduos.

As culturas permanentes levantadas neste estudo são cinco variedades de frutíferas e produziram um total 2.969.760 toneladas de resíduos no ano de 2012. Apesar de o valor total ser expressivo, os resíduos destas culturas já possuem outros usos consolidados, como artesanato, suplementação animal e compostagem. Em estudo realizado por SCHNEIDER et al. (2011), os resíduos da banana, laranja e uva não foram avaliados para uso energético por apresentarem outros usos e já serem largamente utilizados como insumos para outros produtos.

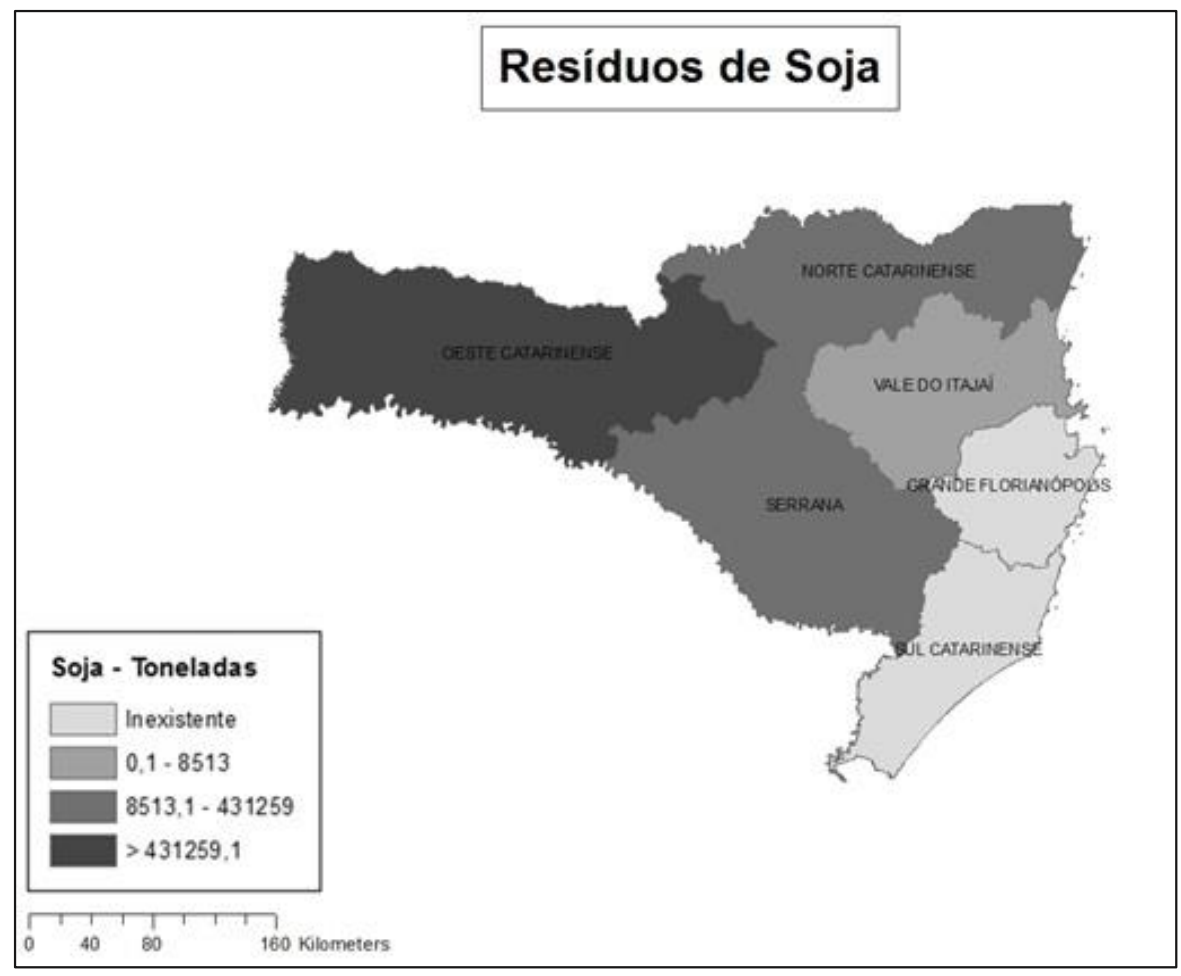

Figura 5 - Mapa ilustrando a disposição dos resíduos da produção de soja nas mesorregiões de Santa Catarina. Figure 5 - Map illustrating the distribution of residues of soya in the mesoregions of Santa Catarina. 
Tabela 3 - Quantidade e localização regional dos resíduos de culturas permanentes em Santa Catarina (em toneladas).

Table 3 - Quantity and location of residues of permanent crops in Santa Catarina (in tonnes).

\begin{tabular}{|c|c|c|c|c|c|c|c|}
\hline \multirow[b]{2}{*}{ Produto } & \multicolumn{5}{|c|}{ Mesorregião } & \multirow[b]{2}{*}{ Sul } & \multirow[b]{2}{*}{ Estado } \\
\hline & Oeste & Norte & Serrana & $\begin{array}{l}\text { Vale } \\
\text { Itajaí }\end{array}$ & $\begin{array}{l}\text { Grande } \\
\text { Fpolis }\end{array}$ & & \\
\hline Banana & 2.042 & 1.562 .549 & - & 889.436 & 42.486 & 265.230 & 2.761 .743 \\
\hline Maçã & 36.448 & 2.505 & 125.854 & 107 & - & 25 & 164.939 \\
\hline Laranja & 19.576 & 343 & 313 & 4.199 & 2.675 & 3.179 & 30.284 \\
\hline Uva & 10.134 & 140 & 653 & 600 & 548 & 708 & 12.783 \\
\hline Abacate & 5 & - & - & - & 5 & - & 10 \\
\hline Total & 68.205 & 1.565 .537 & 126.820 & 894.342 & 45.714 & 269.142 & 2.969 .760 \\
\hline
\end{tabular}

Os resíduos provenientes das atividades agrícolas têm um grande potencial de utilização para a produção de pellets. No entanto, a sua baixa densidade, dificuldades no seu recolhimento e a incerteza na quantificação dos resíduos disponíveis são fatores negativos nesta abordagem. Além disso, é necessário ressaltar alguns problemas técnicos na sua transformação. Por exemplo, a necessidade da biomassa estar sem a presença de contaminantes que possam danificar os componentes de produção (CARVALHO et al. 2013).

Com base nisso, tornam-se necessários estudos específicos para uso dos resíduos agrícolas na geração de energia na forma de compactados. Ainda existem lacunas que precisam ser preenchidas, principalmente no que diz respeito à quantificação mais precisa e métodos específicos para recolhimento dos resíduos no campo para cada tipo de cultura agrícola. Ao mesmo tempo, deve-se criar um procedimento eficaz para o tratamento deste material, antes de entrar no processo de compactação, para minimizar danos aos equipamentos utilizados.

Em contrapartida, a utilização dos resíduos gerados pela silvicultura é mais comum no contexto energético catarinense. CARVALHO et al. (2013), afirmam que a biomassa florestal como fonte de produção de calor é hoje em dia utilizada majoritariamente na indústria, que aumentou a sua utilização na última década, ao contrário do setor doméstico, que a reduziu.

No setor florestal já existe um comércio de resíduos estabelecido, facilitando principalmente questões de transporte e de oferta de matéria-prima para os produtores de compactados. Os resíduos florestais ganharam valor no mercado energético nas últimas décadas, devido a sua qualidade e também versatilidade, podendo ser utilizado de diferentes formas para a geração de energia.

\section{CONCLUSÃO}

A cultura de milho foi a que gerou a maior quantidade de resíduos em 2012, seguida da silvicultura, cultura de arroz e de soja.

As mesorregiões Oeste Catarinense, Norte Catarinense e Serrana foram as que mais geraram resíduos em 2012.

Os resíduos das culturas perenes já são reaproveitados em outras áreas, que concorrem com o uso para geração de energia.

Os resíduos da silvicultura e culturas de milho, arroz e soja são os que possuem maior potencial em termos de quantidade e localização para produção de compactados para a geração de energia.

\section{AGRADECIMENTOS}

À FAPESC - Fundação de Amparo à Pesquisa e Inovação do Estado de Santa Catarina pelo apoio financeiro ao trabalho e à UDESC - Universidade do Estado de Santa Catarina e UNIPLAC - Universidade do Planalto Catarinense pelo auxílio nas pesquisas.

\section{REFERÊNCIAS}

ABIB - Associação Brasileira de Indústrias de Biomassa. 2011. Brasil biomassa e energia renovável. Disponível em: http://pt.calameo.com/read/000200968cc3a949579a0. Acesso em: 18 abr. 2014.

BAZZO E et al. 2013. Resultados da utilização de palha de 
arroz em processo de co-firing com carvão pulverizado. In: 7 Congresso de Inovação Tecnológica em Energia Elétrica. Anais... Rio de Janeiro. CD-Rom

BRAND MA. 2010. Energia de biomassa florestal. Rio de Janeiro: Interciência. 114p.

BRAND MA. 2007. Qualidade da biomassa florestal para o uso na geração de energia em função da estocagem. Tese (Doutorado em Ciência Florestal). Curitiba: UFPR. 169p.

BRASIL. 2010. Lei $\mathrm{n}^{\circ} 12.305$ de 2 de agosto de 2010 . Disponível em: http://www.planalto.gov.br/ccivil_03/_ ato2007-2010/2010/lei/112305.htm. Acesso em: 22 abr. 2014.

CARVALHO AMML et al. 2013. Produção de pellets de madeira. In: SANTOS F et al. Bioenergia e Biorrefinaria - cana-de-açúcar e espécies florestais. Viçosa: UFV. p.379400.

CENBIO - Centro Nacional de Referência em Biomassa. 2012. Atlas de bioenergia do Brasil. São Paulo.

DELLA VP et al. 2001. Caracterização de cinza de casca de arroz para uso como matéria-prima na fabricação de refratários de sílica. Química Nova 24: 778-782.

DIAS JMS et al. 2012. Produção de briquetes e péletes a partir de resíduos agrícolas, agroindustriais e florestais. Brasília: Embrapa Agroenergia. 132p. (Documentos 13).

IBGE - Instituto Brasileiro de Geografia e Estatística. 2014. Produção Agrícola Municipal 2012. Disponível em: http://www.sidra.ibge.gov.br/bda/pesquisas/pam. Acesso em: 25 fev. 2014.

MAYER FD et al. 2006. Gestão energética, econômica e ambiental do resíduo casca de arroz em pequenas e médias agroindústrias de arroz. In: 13 Simpósio de Engenharia de Produção. Anais... Bauru: UNESP.

NONES DL. 2014. Cadeia produtiva de pellets e briquetes de biomassa residual para geração de energia em Santa Catarina. Dissertação (Mestrado em Engenharia Florestal). Lages: UDESC. 124p.

SCHNEIDER VE et al. 2011. Diagnóstico dos resíduos orgânicos do setor agrossilvipastoril e agroindústrias associadas. Brasília: Instituto de Pesquisa Econômica Aplicada. 134p. (Relatório de Pesquisa). 